\title{
Using strategic foresight methods to anticipate and prepare for the jobs-scarce economy
}

\author{
Angela Wilkinson ${ }^{1}$ [D
}

Received: 9 August 2016 / Accepted: 22 October 2016/Published online: 21 November 2016

(C) The Author(s) 2016. This article is published with open access at Springerlink.com

\begin{abstract}
A fundamental shift in the future of work is underway, with significant implications for the number, location, and types of jobs. This shift is entangled in a wider set of longerterm transitions. The disruptive nature of this shift presents new policy challenges and carries implications for maintaining the social contract. This paper shares recent examples of global Foresight that have been developed by the OECD to help national governments to appreciate and prepare for this shift, both individually and via international cooperation. Despite the potential value of using Strategic Foresight methods, a scarcity of strategic conversation at the international level is a key constraint in preparing whole societies for this shift.
\end{abstract}

Keywords OECD $\cdot$ Strategic foresight $\cdot$ Global foresight . Jobs-scarce economy $\cdot$ Self-generated work $\cdot$ Meta-scanning · Scenario planning $\cdot$ Megatrends $\cdot$ Visioning $\cdot$ Strategic conversation

\section{Introduction: a crisis in jobs or something completely different?}

In recent decades, economic globalisation has created millions of new jobs, lifted billions more out of poverty, and led to unprecedented capital wealth. Globalisation has also increased global competition for talent and skills and resulted in the offshoring of jobs - a relocation of manufacturing from the

Angela served as Strategic Foresight Counsellor, OECD until September 2016.

Angela Wilkinson

angelawilkinson@yahoo.com

1 OECD, 2 Rue André Pascal, 75775 Paris, France higher-waged, advanced industrialised economies to lower labour-cost countries. Downward pressure on wages has also increased with the flow of economic migrants.

Today, the future of work is unclear. Increasing connectivity has become a key driver of value and vulnerability. The world has entered an era of faster, more volatile, more turbulent and less predictable change.

On the one hand, the future of work is shaped by the economic turmoil that has occurred following the 2008 great financial crisis. The 2008 crisis has exposed the unsustainable, multiway linkages between the financial services sector, the real economy, wider society and the earth's natural life support systems. For instance, income inequality in OECD countries is at its highest level for the past half century. The average income of the richest $10 \%$ of the population is now about nine times that of the poorest $10 \%$ across the OECD, up from seven times 25 years ago [1]. This development is exemplified by pay cheques to CEOs of multinational companies, which are many thousand times higher than those of average workers. This pattern of greater extremes in income inequality raises new questions about what it means to "fix" the crisis and how to kickstart a more inclusive era of global growth and prosperity.

On the other hand, the so-called Digital Revolution, which started in the 1970 s, is gaining pace. Similar to the Agricultural and Industrial Revolutions, it is destroying lessskilled jobs and creating new opportunities for higher skilled and self-generated work, for example, the rise of the freelancer or gig economy. It also increases existing policy concerns about technology skills gaps, and the rise in long-term and youth unemployment.

This new technological and geopolitical reality is unprecedented. It opens up new possibilities for technological leapfrogs and redirects attention from education for jobs to noncognitive and entrepreneurial skills, life-long learning, and reskilling. It promises massive opportunities in self-generated 
work, including for women and youth. It is also contributing to a heightened sense of job insecurity, and the prospect of an increasing shortfall in decent, well-paid jobs for all. This shift raises uncomfortable questions about the sustainability of the social contract in all kinds of economies, from advanced to developing. It also raises fundamental questions about what it means to "work," the metric of "paid jobs," the goal of full employment as well as the emphasis on income inequality, which has moved to centre stage in the social contact between liberal democratic market states and their citizens.

A fundamental shift in the future of work is underway, with significant implications for the number, location, and types of jobs. This shift is entangled in a wider context - a complex interplay of technological, economic, social, and environmental changes. It is also shaped by the interactions of a more diverse landscape of old and new actors - West and East - a rise in the power of non-state actors and a less benign multipolargeo-polity.

Although longer-term developments are impossible to predict, societies can prepare for the inevitable shift in the future of work. This paper shares examples of recent global Foresight that has been developed by the OECD to help national governments to appreciate and prepare for this shift, both individually and via international cooperation. Despite the potential value of using Strategic Foresight methods, a scarcity of strategic conversation at the international level is a key constraint in preparing whole societies for this shift.

"Measurable changes" section discusses how it is possible to compliment and challenge conventional policy analysis that focusses on the facts about the past, with Strategic Foresight methods that reveal, test and contest assumptions about the future. This in turn enables more futures knowledge to be used to identify and consider new and better policy solutions for dealing with the emerging threats and opportunities implied by the shift in the future of work.

"Using foresight to prepare for the shift in the future of work" section provides examples of how the OECD is using Strategic Foresight approaches to enable flexible framing of the new threats and opportunities of the shift in work and to support more open and inclusive policy conversations about necessary changes in structural policies.

"Discussion and conclusions" section discusses the multiple barriers - cognitive, cultural, behavioural, and institutional - that are encountered in using Strategic Foresight methods to guide policymaking. It highlights how the current scarcity of strategic conversation at the international level prevents new idealism of universal development from becoming a deeper realism.

\section{Measurable changes}

Conventional approaches to policymaking assume a stable and predictable world and use frequency theory to know the distant future by extrapolating statistically significant trends. In this approach the "business-as-usual" future is presented in the form of a probability-based forecast or a non-probabilistic, conditional projection.

This conventional forecast-based planning uses macroeconomic models to calculate the distant future in terms of wages, inflation, (un-)employment rates as well as the numbers, levels, and locations of jobs. Such models are developed to guide progressive structural policies in order to achieve goals such as full employment and higher wages.

The use of mathematical tools for analysis has become easier in recent decades due to the abundance of data and access to cheaper and faster computing power. A good example of these computer-based modelling approaches to strategic threat assessment is provided by recent OECD Employment and Economic Outlooks.

\subsection{OECD business-as-usual outlooks}

Trends in unemployment, long-term unemployment, youth unemployment, underemployment and technological skills biases have been long-standing concerns in many OECD countries for many decades. For example, in the first quarter of 2014, one in three unemployed people in OECD countries had been out of work for 12 months or more, almost twice the number in 2007 [2, 3]. More than half the adults in OECD countries do not have the skills to fulfil simple problemsolving tasks in technology-rich environments [4]. Estimates based on the OECD Survey of Adult Skills (PIAAC) show that on average, $9 \%$ of jobs are at high risk of automation, while for another $25 \%$, half of the tasks will change significantly because of automation [5].

The most recent OECD Economic Outlook [6] offers the business-as-usual perspective that assumes continuity of today's trends. The story created by looking across different sets of data is that a serious slowdown in growth and job creation has occurred following the 2008 global financial crisis. Global growth rates have fallen significantly since 2008 , averaging just $1.7 \%$ in the OECD over the last six years compared to 2.7\% in the 15 years before the crisis. World trade growth has halved following the financial crisis. Advanced economies appear to be stuck in a low-growth trap, wherein diminished expectations about future demand growth become selffulfilling as investment remains subdued even in the face of record-low interest rates. Weak investment growth holds back capital deepening and hinders productivity growth. World trade growth since the crisis has slowed even more sharply among emerging market economies, with some of them falling into prolonged recession. A mix of structural and cyclical factors is implicated in this slowdown and low-growth trap. Based on the current trajectory, the OECD offers a businessas-usual estimate that it will take 70 years, instead of 35 , to double living standards across the advanced economies. 


\subsubsection{The challenge of enabling full employment in the Indian economy}

The future of work outlook for non-OECD economies is similarly challenging. For example, in 2016, the unemployment rate in India is $5.0 \%$ and is projected to increase to $7.5 \%$ in 2017 [7]. Assuming 7-8\% annual growth and based on demographic projections, the economy will need to add over 80 million net new job seekers each year. At current rates only 30 million net new jobs - mostly informal and low-wage ones - will be created [8]. This leaves a gap of about 50 million jobs a year over the next ten years. In response to the "business-as-usual" outlook, Indian Prime Minister Modi has set some very ambitious goals, which include transforming the subcontinent into a "global manufacturing hub" [8] with the aim of creating 100 million jobs in the next six years and spurring the development of a middle class that can power the Indian economy for years to come. But the question remains: how can this shift in the national development pathway be achieved? After all, between 2005 and 2012, India's GDP growth was $54 \%$, but its net job growth was only $3 \%$ - about 15 million net new jobs.

\subsection{Qualitative assumptions}

Such robust econometric projections treat technological development as a black box. The assumption is that new technological developments, similar to those of the industrial era will contribute to economic growth, enhance productivity and create more and higher skilled jobs in the long run. Whether or not this remains true in the future depends on assumptions about the future of technology which are of a more qualitative nature.

\subsubsection{Diverging perspectives on technology as usual}

Present-day outlooks about the implications of new and accelerating technology developments for jobs differ significantly, presenting stories of hope and horror often reflecting the hype of technological determinism, a perspective which assumes technological developments will dictate the nature and pace of social change and not the other way around.

\section{Storyline 1: Secular stagnation: displaced by machines A} combination of factors concerning the productivity levels is based on a long-term historical argument [9]. Therefore, the digital revolution is characterised by the widespread uptake of industrial robots, which accelerates technological joblessness and marks the end of an era of permanent, paid jobs. One study suggests that $47 \%$ of US' employment is subject to substitution by technology; $39 \%$ of Germany's employment; and $35 \%$ of UK's employment [10]. The key policy issue becomes managing social cohesion in the context of fewer jobs and more extreme inequality under conditions of economic contraction.
Storyline 2: New renaissance: machine-augmented There's never been a better time to be a worker with special skills or the right education, because these people can use technology to create and capture value. However, there's never been a worse time to be a worker with only 'ordinary' skills and abilities to offer, because computers, robots and other digital technologies are acquiring these skills and abilities at an extraordinary rate [11]. The alternative perspective is that the accelerating convergence of digital and biotechnologies, with some level of artificial intelligence, will augment human creativity and labour. Machines will do the all the boring, dirty, and unsafe work. There will be more and different opportunities for everyone to create value and to contribute to society.

\subsubsection{Rethinking the society-as-usual outlook}

For most of human history neither paid jobs nor decent work existed. In the last century women managed to have meaningful work without paid jobs, until one-earner families were no longer viable, and homemaking/child-raising/volunteering/ caretaking was not considered meaningful work. A future without paid jobs or meaningful work is, in one sense not a new paradigm for half the population - just for men.

Today the terms "jobs" and "work" appear interchangeable. This was not always the case. For the first time in decades the outlook for jobs and the future of work are not the same thing. The fundamental shift in the future of work cannot be fully understood by using the metrics and models that were developed for the job-centric industrial era. Instead, new threats and opportunities can be better anticipated by looking beyond the facts to engage wider and deeper assumptions that operate as strategic framing devices that shape understanding of the present situation whether or not they are made explicit, or remain implicit.

Without attention to these deeper, and often deeply held, assumptions, informed debates about the future of work can quickly become polarised between all-good versus all-bad stories of the future. For example:

- An impending crisis in jobs due to the rise of robots versus the irresistible rise of the digital economy and the prospect of safer, more interesting work for anyone.

- The inevitable leapfrog of developing and emerging economies versus the inevitable secular stagnation of ageing societies.

\subsection{Working with testable and contestable assumptions, not facts}

Differences in experts' interpretation of data reflect different assumptions about the way the world works and/or should work and what will happen next. In effect, in the absence of 
any direct experience of the future, expert judgement reflects assumptions about the future that are often deeply held and difficult to reveal, test, and contest in the same way as data can be used to verify facts. Since facts are always of the past rather than the future, such differences in informed perspective cannot be easily resolved by simply using more data.

This presents a conundrum to the evidence-based policy system: How to overcome the polarised perspectives offered by expert interpretation of data, even as more and more data is available and how to develop useful and useable sources of futures knowledge? At the same time, policy making cannot simply ignore the existing evidence base or it will run the risk of policy-based evidence, that is, ideologically driven policy ineffectiveness.

By paying attention to alternative stories of the future of work - stories that are already emerging in the present - it is possible to test and contest qualitative assumptions and to engage with strategic frames that would otherwise remain implicit and unchallenged. By working with narratives and numbers and iterating between stories, qualitative systems thinking and quantitative systems modelling, it is possible to develop a more flexible, shared and systemic understanding of the fundamental shift in the future of work.

\section{Using foresight to prepare for the shift in the future of work}

According to UNIDO, Technology Foresight "provides inputs for the formulation of technology policies and strategies that guide the development of the technological infrastructure" [12]. Associated methods take a technology-centric view that focusses on predicting the most likely technological developments in the mid-term future. They can be augmented by Strategic Foresight methods. Strategic Foresight centres on the future from the perspectives of a specific group, community, firm, government or society. The emphasis is not on technology push or pull per se, but on the challenge of developing and using different types of futures knowledge to intervene in puzzling and potentially turbulent situations that are characterised by social ambiguity and systems complexity.

The aim is to test and/or develop strategic options that enhance the resilience of a specified socio-technological system. Strategic Foresight methods engage a diversity of disciplinary- and situated-perspectives and create a safe space to reveal, test and constructively contest assumptions and enable consideration of less familiar future possibilities. The aim is not prediction but better preparedness.

In recent years at the OECD, four different Strategic Foresight methodologies have been used to explore, navigate, and prepare for the shift in the future of work. The "what for" or "so what" of each method is described in the following four sections.

\subsection{OECD meta-scanning: mapping the contours of the next production revolution}

To prepare for unpredictable and potentially disruptive change, it is necessary to look beyond the continuation of statistically strong trends and identify trend bends and breaks, the start of new trends that are already emerging in the present. This is enabled through scanning the horizon, that is, looking beyond the usual timeframe of decisionmaking and beyond the extrapolation of today's trends that are relevant when using a strategic frame of full employment and paid jobs.

In 2014, the OECD Strategic Foresight unit piloted a globally, wide and deep horizon scan of multiple sources of data (a meta-scan) to help frame and inform a new strategic and horizontal work programme on the Next Production Revolution. The meta-scan inputs were three-fold: (1) Targeted search for recently published (within 5 years) Foresight reports by member and partner governments; (2) An extensive search of academic databases; (3) An open scan of internet sources and social media.

The targeted search revealed the globally common and different national emphasis that is being placed on emerging technologies. For example, robotics, nano- and biotechnology dominate literature about technologies, accounting for $38 \%$, $32 \%$, and $25 \%$, respectively, of articles. One quarter of all results originated from the United States, with China accounting for $11 \%$. Other leading countries (in order) were Japan, Germany, the UK, South Korea, France, Italy, India, and Canada. More articles about the Internet of Things, however, came from China than from anywhere else, with the USA leading on the other three technologies.

The open scan was produced in collaboration with the firm Polecat, which used its proprietary platform (Meaning Mine), which tracks millions of sources of unstructured data each day, including online national and local news, blogs, forums, trade publications, consumer reviews, press wires as well as corporate, government and academic publications from over 180 countries. The open scan included all online and social media in English over 90 days and covered Big Data, Internet of Things, 3D printing, nanotech, robotics and industrial biotechnology.

The headline results were as follows:

- Healthcare impacts dominate online and social media, followed by robotics and jobs.

- Online media coverage of all technologies was more positive than social media.

- Environmental impacts tend to be less visible, save for industrial biotechnology.

- Corporate involvement is cross-sectoral: aeronautics, automobiles, banking, consumer goods, crop science, ICT, lifestyle, oil and gas, and pharmaceuticals. 
- The significance of these technologies and the perception of benefits and threats vary on a regional basis.

Combining the targeted search and scan elements and using data mining of the results of both enables policymakers to better avoid the trap of technological determinism and to attend to the social pull factors of new technology developments. In the pilot meta-scan the combination of technological push and social pull factors was concentrated in five challenge themes (Fig. 1)

By looking beyond individual national perspectives and across multiple policy domains, the meta-scan directs attention to new themes and global connections that are relevant in preparing societies for the shift in the future of work. Horizon scanning can also be facilitated by using a megatrends framework that helps facilitate shared and faster sense-making of new and different stories, signals, and novel developments.

\subsection{OECD megatrends analysis}

Megatrends are not single trends but an analysis of the pattern shifts that will result from the interplay of multiple trends. OECD megatrends analysis is used to set the scene for highlevel policy meetings. An OECD megatrends analysis enables a shared view of the shifting global strategic landscape and can be used to support interactive and generative policy dialogues on a wide range of existing and emerging challenges.
The OECD megatrends framework was established in 2012 and is organised around four broad categories, namely People, Planet, Productivity and Polity. A fifth cross-cutting theme Progress - can be added if horizon scanning involves attention to new and different narratives of progress and an analysis of underlying myths. These broad categories act as lenses that focus on different parts of the vast future landscape in order to enable new insights about interacting trends. Each category also operates as a bridge that links synthesis across policy silos and different national perspectives. For example, demographic ageing is an established megatrend in many OECD countries. By 2050 , the number of people aged 65 years and older will have tripled. Meanwhile the percentage of the population aged 16 years and under is shrinking. Demographic ageing has emerged from a combination of improvements in health, welfare and work. It carries significant implications for the future of work - an ageing workforce, the sustainability of pensions, etc.

However, a demographic shift is not the only Peoplecategory related megatrend that needs to be considered, especially in facilitating global economic cooperation and development. In addition to demographic ageing in OECD countries and China, the OECD People megatrend lens identifies other people-related pattern shifts:

- Youth bulges are emerging in many non-OECD countries, i.e. the majority of the population aged less than 16 years can be found in some of the fastest growing populations, e.g., Indonesia, and, Nigeria.

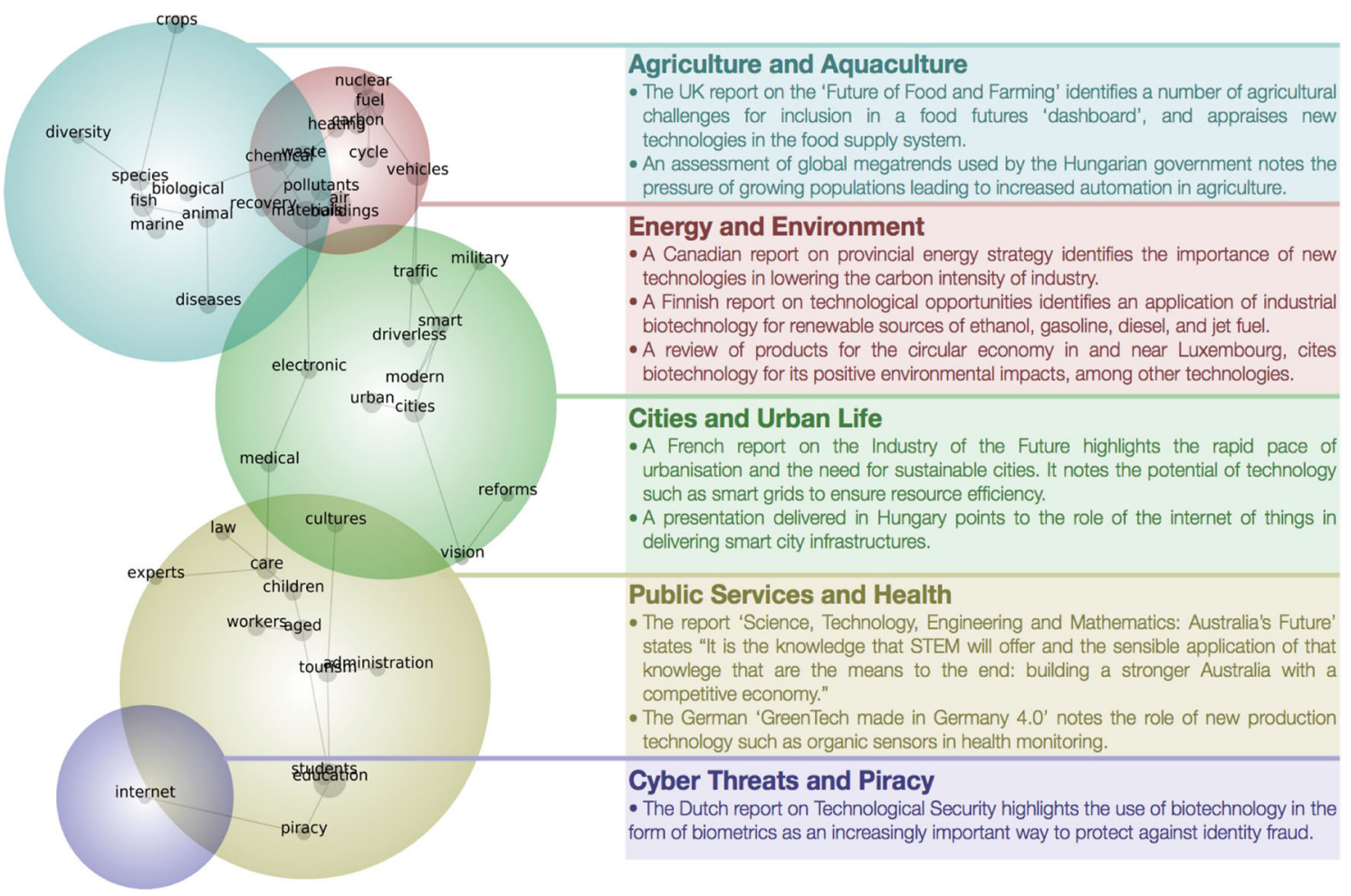

Fig. 1 Visualisation of the OECD Meta-Scan on the Next Production Revolution. Source: Strategic Foresight Unit, OECD 
- Rapid urbanisation in many emerging economies, contrasts with peaking of urban populations in cities in some OECD countries. By 2020, most of the world's top 20 megacities will be located in non-OECD countries, and there will be 500 new mid-sized cities (1 million-plus inhabitants) in China.

- Increasing pressure for and new patterns of migration globalisation has reduced income inequality between countries yet even modest wage differentials drive economic migration. Unprecedented waves of people-movement are occurring in different world regions - within Asia-Pacific, between Central and North America, between the Middle East and Europe. More lone children and families are forced to relocate due to war, extended conflict and foodand water-related environmental crisis (famine, flooding).

- Connectedness - the rapid increase in the use of social media as evident in the widespread use of Facebook, Twitter, etc. More people in Africa now have a mobile phone than access to electrical grids. Even so, four billion people worldwide are not yet online.

In effect, the People lens redirects attention from the focus on ageing societies that has characterised international policy discussions on the future of work in the past, to addressing the new phenomenon of more globally connected and demographically diverse societies.

Similarly, the OECD Productivity lens encourages attention to new signals of change relating to developments in education, skills and technology (digital and other). For example:

- In recent years, there has been an intensified polarisation of today's workforce between highly-skilled, well-paid jobs and lower-paid, low-skilled ones even as the share of the low-educated has been contracting across all major occupational groups [12].

- Technology developments that augment human labour and cognitive skills and create new types of work, e.g., a "micro-facturing revolution" enabled by 3D printing, machine-machine learning, and the development of generalised artificial intelligence.

- The rise of the shared (or peer-to-peer) economy enables individuals to leverage their skills and assets (e.g., cars). As a result, there are new opportunities for self-generated work including for women and youth, at least for those with some assets.

- Driverless cars, drones delivering goods, and algorithms replacing accountants, bank staff, and legal assistants have led some to suggest that automation will result in a net loss of more than 5.1 million jobs across 15 major advanced economies [13].

Looking slightly further forward, the digital revolution is accelerating a pattern of technological convergence. Digitalisation is not happening in isolation but in interaction with other technology fields (nanotech, biotech, ICT, genetics, robotics, and artificial intelligence). This is creating a new reality - decentralised, pervasive, embedded and active - "living" technologies, and the prospect of an Internet of Everything, machine-machine learning and robotic innovation. The nature and timing of the next productivity revolution are uncertain and dependent on assumptions about the speed and inevitability of the transition from the industrial to digital knowledge economy.

The future of work is also shaped by developments in finance, business and trade. For example:

- The long-term costs of capital and continuation of zero and low interest rates;

- The uneven uptake of new technologies by firms and the staff-light business models of the new internet business giants;

- In addition to the reduction in world trade since 2008, there is a shift in what is being traded from manufactured products to intermediaries (e.g., software) and services. Could the current slow progress in international trade rounds, which are focussed on the liberalisation of services, soon be outpaced by digital disruption of what will be traded in future? If so, where and by whom?

\subsubsection{Megatrends crashing - navigating demographic diversity and new productivity dividends}

In addition to considering the implications of developments within each megatrends category for the future of work, new threats and opportunities can be anticipated by combining megatrend categories - e.g., People and Productivity. This enables, in turn, different global perspectives concerning the shift in the future of work to be discovered and considered and avoids the trap of imposing a "one size fits all" global blueprint. For example, emerging economies are rethinking demographic dividends in the context of digital divides, and advanced industrialised economies are grappling with the digital dividend in the context of rapidly ageing societies.

\subsection{Scenario planning - exploring alternative futures}

\subsubsection{OECD futures of livelihoods}

In 2014, the OECD Development Centre in collaboration with The Rockefeller Foundation embarked on a scenario-based project called "Securing livelihoods for all: Foresight for action." This initiative was motivated by two shared challenges:

1. To develop inclusive economies that would enable the poorest and most vulnerable to access global opportunities.

2. To create secure livelihoods that enable individuals, families and communities not just to survive but to thrive in the face of emerging threats. 
The scenario planning framework was developed during a four-day workshop held at The Rockefeller Foundation's Bellagio Centre in August 2014, which gathered an expert group of entrepreneurs, scholars, policymakers and nonprofit leaders to discuss the future of livelihoods. The workshop was co-organised by The Economist Intelligence Unit and the OECD Development Centre as part of The Rockefeller Foundation's Visionaries Unbound series.

Four sketch scenarios emerged from workshop discussions, developed around two axes that represented key uncertainties in terms of the following questions: (1) "Will the future of livelihoods be determined by large-scale solutions? Or by solutions at the local level, especially cities?" (2) "Will the future of livelihoods be focused primarily on getting policies right? Or, by becoming more effective in the developing of individuals for a new work world?"

Nets - the financial economy Jobless growth is accepted as a facet of late-stage capitalism, and policymakers look to social safety nets to assure livelihoods for all. There is increasing interest in radical redistribution policies - including restructuring of domestic tax systems to enable a shift from income to consumption and wealth taxes and piloting of new systems involving Basic Income Guarantees.

Pathways - the knowledge economy The knowledge economy grows, so there are plenty of jobs - but they all require education and training. There's a mismatch between jobs and education, which governments and cities struggle to correct. There is much more focus on re-training of older workers and helping young people get the necessary skills and guidance.

Portfolios - the experience economy Young people are no longer interested in jobs so much as meaningful work, worklife cycle balance, and portfolio careers. Entrepreneurs sell their services, skills, and produce directly to global markets, on e-bay and through Alibaba. Dematerialisation accelerates in advanced industrial societies but with an increase in global tourism, due to the growing focus on an experience economy by global connected urban elites.

Green world - the green economy Nations make large and serious commitments to building low carbon and digital economy infrastructures - creating jobs at all levels in a way similar to the rebuilding efforts after World War II that made formerly devastated countries (Japan, Germany) among the most prosperous.

The four scenarios offer different possible futures from the one currently being forecast. They do not depend on miracles of global governance. But they do depend on a shift in emphasis by policymakers from an exclusive focus on GDP growth to one that also takes into account the multidimensional well being of people. These four sketch scenarios continued to be developed through an iterative process of storytelling, systems thinking, and quantitative analysis involving engagement with wider OECD experts. The final set of five scenarios explicitly reflected financial and environmental shocks and were used by policy analysts to identify policy implications at the global, national, and local level for the future of livelihoods under very different circumstances [14].

\subsubsection{OECD ministerial committee meeting: futures of investments and jobs}

Another example of using a scenario-based Foresight intervention to anticipate the shift in the future of work centres on the preparation for an informal and interactive scenariobased policy discussion session about the direction of national policies aimed at unlocking investment for sustainable growth and jobs, which took place during the first lunch of the OECD's annual Ministerial Council Meeting in June 2015. Three global archetype scenarios were identified by the OECD secretariat based on an expansive review of global scenarios published by governments and businesses. These were further developed through engagement with national Foresight experts and fine-tuned via an extensive prototyping of the interactive discussion process involving OECD ambassadors and delegation staff.

The three global archetype scenarios present alternative future policy contexts that might happen to OECD member countries and partners, independently of what they - or the OECD as an organisation - think should happen.

A brief description of each of these three archetype scenarios is presented in the remainder of this section together with the implications of each for the future of work.

\section{Quick fixes Globalisation continues with faster incre- mental policy adjustments enabled by greater transparency and data abundance.}

In Quick Fixes, policymakers scramble to balance the need for more flexible labour markets with the need to avoid more extreme income and wealth inequalities. Jobless growth is increasingly accepted as a facet of late-stage capitalism, and policymakers look to radical redistribution mechanism, including high wealth taxation to enable investment in livelihoods for all. In a world of digitally empowered but increasingly fragmented and polarised societies, implementation of new policy experiments centred in the concept of "universal basic income" is delayed until after 2025. Many young people in mature industrial economies are no longer interested in lifelong jobs so much as meaningful work, work-life cycle balance, and portfolio careers. As more and more entrepreneurs sell their commodities online from developing, emerging and advanced economies, policy makers are faced with a new challenge that not everyone wants or can be an 
entrepreneur. By 2030 two billion are employed, two billion are self-employed, one billion are in the informal economy, one billion are unemployed or in transition, and two-and-ahalf billion people are not part of the workforce (children, retirees, people with disabilities).

Multipolar The global order is starting to fragment, as regional agreements proliferate and groups of countries choose different technology and regulatory pathways in pursuit of growth and well-being.

In Multipolar, the opportunities of low interest rates and more diverse sources of private credit enables governmentdirected investment to be targeted at job creation in new "sunrise industries" that meet shifting social needs and are acceptable from the perspective of ethics and cultural values. Nations make large and serious commitments to building the new 'clicks-and-bricks' infrastructure that is needed to support new innovation ecosystems, at regional and national scale. This creates jobs at all levels in a way similar to the rebuilding efforts after World War II that made formerly devastated countries (Japan, Germany) among the most prosperous. As national economies start to grow again, there are plenty of jobs - and they all require broader skills. Cognitive enhancements and machine-augmentation of humans are carefully regulated to avoid new social gaps and divides. There is growing conviction that there are more jobs available than there are skilled people to fill them. Education systems rapidly transform to meet the challenges of learning for life and lifelong learning.

\section{City power Globally connected cities compete with one} another to attract the best talent and the most successful corporations from around the world. More dynamic cooperation between cities, businesses and governments enables new solutions to emerging global challenges such as climate change adaptation, robotic innovation, cyber-security, and increasing migration.

In City Power, new technologies stimulate more selfgenerated work opportunities, and 3D-printing results in a reshoring of work. As successful cities increasingly attract global investment in smarter, integrated and urban-scale food-waterenergy systems, livelihood policies are developed at the city level and aligned with new national frameworks that support managed migration, global cyber security and mega-regional trade systems. Companies outsource work in discrete projects, so workers may sometimes be working at a couple of projects followed by a period during which they have no employment. In an era of robotic innovation, monopolies of knowledge are a continuous problem as fewer companies register patents. National governments learn to regulate new types of selfgenerated work, to provide incentives for the use of private data for public goods and to develop new frameworks for measuring contributions to society beyond income generation.

These scenarios do not directly provide solutions but, as a set, helped to highlight new questions for discussion that are relevant to a more anticipatory global policy agenda on the future of work, for example:

- What new metrics of productivity are needed in a jobsscarce economy?

- If the best opportunities for unlocking investment for sustainable growth occur at a regional or city level, what new global governance arrangements will be needed?

- How can the global knowledge commons be safeguarded an era of private data and robotic innovation?

\subsection{Visioning and back-casting - translating universal development into actionable policies}

A new global vision of universal development in which no one is left behind has been agreed and is underpinned by the UN agenda on 17 Sustainable Development Goals (SDGs).

Translating this vision into action is the task of national governments. Several OECD governments have started to review and align existing national development strategies or to create new ones that will enable them to meet and demonstrate that they are meeting their new international commitments.

Central to these efforts is a whole-of-government agenda that anticipates how the shift in the future of work is being shaped by the complex interplay of global and domestic factors and national policy choices. To support its members' efforts, the OECD, in turn, has developed more integrated methodologies that combine conventional policy analysis, Strategic Foresight methods, and multidimensional measurement frameworks. These new integrated methodologies are not confined to OECD members but include the Multi-Dimensional Country Review process for use in developing countries.

An example of how progress on commitments to the new global vision of universal development manifests in implications for the national policy agenda on the future of work is provided by Slovenia. Slovenia is in the process of preparing the National Development Strategy 2030 in accordance with its Vision 2050. Both the vision and the strategy are being created with a focus on implementation of the UN Agenda 2030 for Sustainable Development.

The Slovenia Vision 2050 was developed through a participatory Foresight process to ensure a whole-of-society vision and drew on range of initial analytical inputs about the domestic situation, outlook and shifting global context. To provide relevant inputs, the Slovenian government asked the OECD to 
produce an independent comprehensive assessment of the current situation, which included a comprehensive analysis of key domestic trends and comparative international performance. It was supplemented by an analysis of megatrends, global and regional scenarios, and disruptors.

The drafting of the final vision statement continued through several rounds of dialogue with key policy shapers and wider stakeholders in government, Parliament, businesses, and the wider society. The new national vision does not focus on the future of paid jobs per se, but describes a new inclusive value-creation system that can sustain peace and shared prosperity in the shift from an industrial to a knowledge-based society. The motivating nature of the vision generates new social energy and supports multiple strategic conversations within and between different key stakeholders in the government, Parliament, business and wider society that brings together issues of jobs, self-generated work, and challenges of pensions and immigration, in a way that supports a generational value shift in a highly educated society: a move away from a jobs-for-life culture to choices that enable more contributions to society and better work-life cycle balance.

For example, the vision recognizes the importance of enabling a transformation in education - a redesign of the system and curriculum - to enable skills for life for all of society rather than education for jobs per se. Skills for life, in turn, involve cognitive and non-cognitive elements and contribute to creative problem solving, entrepreneurship, and active citizenry. Furthermore, the vision opens up the space for a policy dialogue on labour market flexibility from the perspective of the worker rather than the employer.

What is becoming clear in moving from visioning to action is that navigating the shift in the future of work is a crosscutting agenda, not limited to the ministry of education or social policies but benefitting from engagement of other ministries and policy domains.

Translating the vision into coherent policies that are linked to budget and performance cycles has also exposed the lack of whole-of-government capacity, which is common in the stove-piped silos of bureaucratic and hierarchically organised national governments. New mechanisms for horizontal cooperation are being progressed that use the Vision 2050 and Strategy 2030 as a safe space to cultivate the "people coherence" that is necessary for progressing a whole-ofsociety vision through a whole-of-government agenda that anticipates a fundamental shift in the future of work.

\section{Discussion and conclusions}

\subsection{Preparing for - not predicting - the shift in work}

A fundamental shift in the future of work is occurring, which can be characterised as the end of the era of full employment and paid jobs and the start of a technologically enabled era of self-generated work. This shift is not determined by technology per se but is shaped by the value, choices, and interaction of a diversity of social actors and wider factors. It is entangled in a wider context of global shifts.

Whether or not the future of work is good, bad, or ugly is impossible to predict and difficult to discuss. It surfaces uncomfortable questions about the present situation - for example, the relevance of paid jobs as a key unit of analysis or the validity of existing macro-economic models that were designed for an era of full employment.

Many of the contours of the still emerging "jobs-scarce economy" and the "self-generated work society" are not yet visible. Detection of the new, emerging contours of the future of work benefits from attention to the framing of relevant trends and data. This framing inevitably reflects deeply held assumptions about the future. Assumptions about the future are inherent in understanding the present situation and hard to reveal, test, and contest. A key challenge in policy-making is not simply the absence of data about the future but the challenge of engaging assumptions and improving the quality of inter-subjective judgements.

This shift cannot be fully anticipated, appreciated, or addressed by projecting the past into the future. Anticipating fundamental changes in the number, nature, and location of jobs and the new opportunities for machine-augmented and self-generated work requires more imaginative, as well as integrated and inclusive policies. This can be achieved by looking beyond the facts and engaging with assumptions. Revealing, testing and contesting future assumptions can promote new, shared and more systemic policy learning.

As the examples provided in this paper indicated, new solution spaces can be identified by using Strategic Foresight methods to supplement conventional policy analysis. The new solution spaces are often cross-cutting and identifying and populating them benefits from strategic conversation, not just more and better analysis.

For example, some of the emerging threats and opportunities of this fundamental shift involve managing skills gaps and jobs scarcity in the context of a still accelerating pace of technological change, whilst avoiding a low growth trap. It will benefit from bringing together expertise in trade, finance and investment, and economic and social policy. It will require courageous leadership to open up a higher quality strategic conversation about radical redistribution mechanisms, sunrise and sunset industries, the redesign of education systems, and global migration.

In the absence of any predictive theory of evolution, strategic and other foresight methods offer a pragmatic toolkit that can be used to navigate the messy multidimensional shift in work and avoid the trap of framing the future in terms of the repetition of history, conventional wisdom, and solutions that worked in the past. 


\subsection{The need to overcome multiple barriers}

The effective use of Foresight methods - whether the focus is on technology- or organisational- focussed futures - is not a simple matter of the substitution of old methods and tools for new. There are multiple barriers to developing and using Foresight to complement and challenge conversational policy analysis on the future of work and significant problems in assessing and evaluating impact.

\subsubsection{Multiple barriers}

To identify and overcome these barriers and problems, the OECD started to convene an international community of senior government Foresight champions and experienced practitioners in 2013. The community network has grown rapidly to include over 70 members from 23 OECD member states and key partner countries. In additional to facilitating international exchange of global- and governmental Foresight studies the community is engaged in an exchange of "stories of success" - real world examples of effective use and impact of Strategic Foresight by governments. These cases include the use of Foresight for many different purposes: national risk assessment; development national security and development strategies; engaging orphan issues (i.e. emerging policy challenges that fall between the silos); resetting research agendas; enabling strategic early warning systems; building social capital; and, testing existing/designing new policies.

The community collaboration is enabled via a web-portal and platform, as well as face-to-face working group meetings and an annual conference.

To date, the OECD Government Foresight Community (GFC) network has identified four types of barriers to the development and use of Foresight - cognitive, cultural, behavioural and institutional. Cognitive barriers include: spatial horizon (state/local centred, absolute notion of space); issue horizon (sectoral silos of regulatory responsibility); dynamic horizon (trend continuity); and, ethical horizon (policymaking as rational project, bounded by invariable outputs). Cultural barriers include: an inherent bias towards the short-term (political myopia, presentist bias); and, drive for consensus/avoidance of conflict. A key behavioural barrier is that there are incentives for stepping up in crisis, but none for avoiding crises. Institutional barriers include: lack of effective engagement with gatekeepers in the policy briefing hierarchy (late involvement, poor translation); no/limited whole-of-government network capacity; skills in working with numbers and narratives, in designing and facilitating strategic conversations, etc.

\subsubsection{Assessing and evaluating impact}

There is no scientific or widely agreed procedure for assessing and evaluating the impact of Foresight in policy. After all, the aim is not enable more accurate prediction but to enhance preparedness. The assumption in developing and using Foresight in policy making is that the future cannot be fully predicted and thus all decision outcomes cannot be calculated in advance. Added to this, of course, is the reality that the actual process of policy-making in practice does not conform to the idealised model of truth speaking to power i.e. there is a challenge of using more evidence at the same time of needing to look beyond the "facts". Finally, cause-and-effect in decision-making processes are complex. Foresight is one of many inputs in a process that is shaped by different cultures of decision making vary in terms of how a decision is made and what constitutes a decision.

As a consequence, the GFC community continues to engage with scholarship into the use and evaluation of Foresight, including grounded theory that has been published to guide effectiveness of scenario planning practices. It has noted that similar theory for the effective use of mega-trends analysis does not yet exist. This presents an opportunity for further scholarship to support the continued evolution and effectiveness of the development, use and impact of the diversity of methodologies that characterise the practice-led field of Foresight.

\subsection{Strategic conversation at the international level to move beyond idealism to deeper realism}

Individual governments can better prepare societies for the emerging job-scarce economy by developing and using global foresight.

In an era still characterised by global economic integration and interconnectedness, there are limits to the effectiveness of national strategies in anticipating the shift in the future of work and benefits in international collaboration. Collaborative action at the international level needs to respect different perspectives and move beyond national interest. It benefits from not only the exchange of national perspectives of the global future but on the inclusive development and use of neutral Global Foresight.

To prepare for a faster, fundamentally shifting, and more interconnected world, which is increasingly global and local, and shaped by actors within and beyond government, the OECD is developing and using global foresight to get ahead of emerging global policy challenges and enable anticipatory global governance.

The concept of global Foresight is still in its infancy. It requires a blending of strategic and technological foresight approaches with conditional projection. Global futures knowledge can be enabled by working with narratives and numbers to test and contest facts and assumptions. Futures knowledge is not the same as the fact-based knowledge enabled by reflection on past experience. It is never right, but nevertheless useful. 
A good quality strategic conversation is required to generate, legitimise, and use global futures knowledge. A mix of objectivity, creativity, and empathy is required to forge global common ground and sustain new and more effective collaboration.

Strategic conversation enables a more open, explicit, shared, and flexible sense of future to be developed through a process of interactive and immersive learning that takes place in imagined future situations. Good conversation cannot breathe in the ritualistic rain dances of governmental bureaucracy or international diplomacy or the point-and-counter point debates of the academy. Nor can it flourish in the void of competing global agenda of international organisations.

In preparing societies for a fundamental shift in the future of work - and to get ahead of globally connected challenges emerging from other global shifts - the challenge is to overcome the polarised, incremental character of current debates and enable a good quality strategic conversation that benefits from the inclusive and collaborative development and use of Global Foresight.

Acknowledgments This article presents a personal perspective and does not represent an official view of the OECD, or the views of its individual member countries. It has been prepared with the assistance of Dr Betty Flowers and Joshua Polchar.

Open Access This article is distributed under the terms of the Creative Commons Attribution 4.0 International License (http:// creativecommons.org/licenses/by/4.0/), which permits unrestricted use, distribution, and reproduction in any medium, provided you give appropriate credit to the original author(s) and the source, provide a link to the Creative Commons license, and indicate if changes were made.

\section{References}

1. OECD (2011) Divided we stand: why inequality keeps rising. Organisation for economic co-operation and development. http://www.oecd-ilibrary.org/content/book/9789264119536-en. Accessed 10 Oct 2016

2. OECD (2014) OECD Employment Outlook. OECD Publishing. http://www.oecd-ilibrary.org/employment/oecd-employmentoutlook-2014_empl_outlook-2014-en. Accessed 10 Oct 2016
3. Eurostat (2016) Unemployment Statistics. Statistics Explained. http://ec.europa.eu/eurostat/statistics-explained/index. php/Unemployment_statistics. Accessed 10 Oct 2016

4. OECD (2013) OECD Skills Outlook. Organisation for Economic Co-operation and Development. http://www.oecd-ilibrary. org/content/book/9789264204256-en. Accessed 10 Oct 2016

5. Arntz M, Gregory T, Zierahn U (2016) The Risk of Automation for Jobs in OECD Countries. OECD Social, Employment and Migration Working Papers. http://www.oecd-ilibrary.org/socialissues-migration-health/the-risk-of-automation-for-jobs-in-oecdcountries_5jlz9h56dvq7-en. Accessed 10 Oct 2016

6. OECD (2016) OECD Employment Outlook. OECD Publishing. http:/www.oecd-ilibrary.org/employment/oecd-employmentoutlook-2016_empl_outlook-2016-en. Accessed 10 Oct 2016

7. IMF (2016) World Economic Outlook Update: Subdued Demand, Diminished Prospects. ht t p:// w w w i mf. org/external/pubs/ft/weo/2016/update/01/pdf/0116.pdf. Accessed 10 Oct 2016

8. Wadhwani R (2016) India's Jobs Crisis: Here's a Plan for Creating 50 Million Quality Jobs in the next Decade. Times Of India Blogs. http://blogs.timesofindia.indiatimes.com/toi-edit-page/indias-jobscrisis-heres-a-plan-for-creating-50-million-quality-jobs-in-thenext-decade/. Accessed 10 Oct 2016

9. Gordon R (2012) Is U.S. Economic Growth Over? Faltering Innovation Confronts the Six Headwinds. National Bureau of Economic Research. http://www.nber.org/papers/w18315.pdf. Accessed 10 Oct 2016

10. Frey CB, Osborne M (2013) The Future of Employment: How Susceptible Are Jobs to Computerisation. http://www. oxfordmartin.ox.ac.uk/downloads/academic/future-ofemployment.pdf. Accessed 10 Oct 2016

11. Brynjolfsson E, McAfee A (2016) The second machine age: work, progress, and prosperity in a time of brilliant technologies. W.W. Norton \& Company, New York

12. OECD (2015) In It Together: Why Less Inequality Benefits All. OECD Publishing. http://www.oecd-ilibrary.org/employment/in-ittogether-why-less-inequality-benefits-all_9789264235120-en. Accessed 10 Oct 2016

13. World Economic Forum (2016) The Future of Jobs: Employment, Skills and Workforce Strategy for the Fourth Industrial Revolution. Executive Summary. http://www3.weforum.org/docs/WEF_FOJ_ Executive_Summary_Jobs.pdf Accessed 10 Oct 2016

14. OECD (2015) Securing Livelihoods for All: Foresight for Action. Development Centre Studies. OECD Publishing. http://www.oecdilibrary.org/development/securing-livelihoods-forall 9789264231894-en. Accessed 10 Oct 2016 